Anri van der Spuy*

\title{
Mirror, mirror upon the wall - is reality reflected at all?
}

\begin{abstract}
Journalists often argue that their role in a society is to provide content that merely reflects reality. The critical theories regarding the media's role in society however suggest that the media are carriers of dominant ideologies, thereby "reflecting" that which is favourable to the dominant party in a society. Normative theories, on the other hand, suggest that political and social structures have a vast influence on the different things that may be expected of the media. Is it perhaps time that the media realise that that which their mirror reflects, is not reality at all?
\end{abstract}

\section{Keywords:}

Critical theory; ideology; media; mediation; news construction; normative theory; reality; role; society.

*Anri van der Spuy [14089432@sun.ac.za] is a student at the University of Stellenbosch, PO Box 12384, Die Boord, Stellenbosch, 7613. Tel: 083566 4524; Fax: 0218802281. 


\section{INTRODUCTION}

Children sometimes play a game, 'telephone-telephone', where a phrase is whispered from one child to the next. By the time the last child in line hears the message, the sentence he or she recites is dramatically different from the original phrase. Similarly, one often wonders whether reality actually corresponds to that which is translated by the media to society as being 'reality'.

Although there will always be debates about what specific role in mediation the media fulfils, and also what role the media should fulfil in a society, one thing is certain. As noted by Denis McQuail (2005:81) 'there can be little doubt that the media, whether moulders or mirrors of society, are the main messengers about society'.

In modern society the media can be said to assume the earlier roles of, for example, schools, religion and the state to help people make sense of reality. 'The media to a large extent serve to constitute our perceptions and definitions of social reality and normality for the purposes of a public, shared social life and are a key source of standards, models and norms' (McQuail, 2005:81).

Due to the important role that the media can therefore fulfil, it is important to review the role that the media purport to play and the one actually fulfilled in the end - these two are often as different as the original message whispered by the first child in the telephone-game versus the one recited by the child last line.

\section{THE MEDIA AND/OR THE MEDIA IN SOCIETY}

Society is defined by McQuail (2005:78) as the 'material base (economic and political resources and power), to social relationships (in national societies, communities, families etc) and to social roles and occupations that are socially regulated (formally or informally)'. In a sense one can thus argue that society forms the basis of everyday experience; the fabric of human life.

One would like to think that the media form a bridge between society and reality, translating versions of events which society's inhabitants cannot perceive for themselves. This supposed 'bridge' has very strong foundations in society, however, as media institutions form 'part of the structure of society and its technological infrastructure is part of the economic and power base, while the ideas, images and information disseminated by the media [as reality] are evidently an important aspect of our culture' (McQuail, 2005:78).

The extent to which the media is viewed as part of society differs:

- A materialist view, which forms the basis of the Marxist theories, regards the media as an aspect of society, being "dependent on the economic and power structure of a society";

- An idealistic approach, on the other hand, regards the media as primary moulders of society, having the potential for "significant influence" (see p. 12);

- Another approach regards the media and society as interdependent, "continually interacting and influencing" another; and

- Media and society can also be viewed as independent of another (autonomy) the media having little power to influence society (McQuail, 2005:79-80).

\section{MIRROR, MIRROR UPON THE WALL}


The manner in which the media's versions of everyday events are communicated, or the way in which 'the media facilitates our contact with social reality' can take various different forms, depending on the situation (McQuail, 2005:83). Each of these forms also correlate to either a larger or lesser degree of interdependence (see above) between the media and society.

The media's mediation role can take place in the form of a window on events, allowing society "to see without interference"; or in the form of a filter or gatekeeper, where only certain aspects of an experience is selected and others are discarded. The media can also act as a platform, whereby ideas are presented to society; a disseminator which merely passes on information or an interlocutor - an 'informed partner that responds to questions' (McQuail, 2005:83).

Journalists will often argue that mediation merely takes place in a form that resembles a mirror, "implying a faithful reflection" (McQuail, 2005:83). According to this approach, that which is read in newspapers and on the Internet, heard on radios and seen on televisions merely reflects that which occur in reality.

On 18 April 2008 Die Burger, a daily Afrikaans newspaper, placed a photograph of the naked bodies (lying face-down in an open field) of two murdered men, Brett Goldin and Richard Bloom, under the heading 'Crazy-moorde' (Crazymurders). The newspaper was severely criticised by South African citizens, and Ed Linington, then the South African ombudsman, received various complaints on the grounds that the image was "insensitive" and showed clear disrespect for "both the victims and their surviving families' (Maggo, 2006:2).

Arrie Rossouw, editor of the newspaper at the time, argued that the photograph was justified in being a reflection of the state of crime and gang violence occurring in South Africa. 'We thought we should place it (the photographs) so as to show people what is going on in the beautiful Cape Town' (Taljaard, 2006:4). He explained: 'We do not want to camouflage news, we want to show people what death and violence looks like' (Taljaard, 2006:4).

Rossouw's argument is a typical example of the media supposedly "holding up a mirror to society”. But, unlike the mirror in the Grimm brothers' tale of SnowWhite and the seven dwarfs, however, the media's mirror not only does not reflect the fairest of them all, but also rarely reflects them all.

The image presented by the media's mirror is often distorted and the particular angle of reflection can also be 'directed to produce only a fraction of the original image’ (McQuail, 2005:83). As such, the picture reflected by the media is generally only a part of reality, and also only the reality the media perceive as reality.

\section{FRAMING AND NAMING THE NEWS 'REALITY'}

The way in which news is selected is a good example of how only a fraction of reality is conveyed to society. Occurrences and events only become news once it is selected, and news is generally constructed following a selection-recipe using typical news values such as proximity, prominence and human interest - none of which are neutral. These news values influence society's understanding of the world by also deciding what is important enough to be regarded as news and what is not (Wasserman, 2007:1).

Framing plays an important role in this process of news selection. Frames are 'used by news workers to transform the daily news glut into orderly raw material that they can process and disseminate', thereby 'organising reality' (Fourie, 2005:457) or, as one can argue, organising a certain part of reality. 
The basic building blocks of this selective construct of reality are language. News is thus not just a reflection of a part of the world, but also a representation of a part of the world in language (Wasserman, 2007:1). It is important to note, however, that language itself is anything but neutral. Language does not mirror reality 'meaning is arbitrary, not fixed, decided upon socially and within context' - as Wasserman argues, language rather 'projects' reality (2007:1).

\section{IDEOLOGY}

Language can also be used to mask hidden ideologies within the media, which means that the media, as an aspect of the society often carries far more meaning in their messages than they perhaps realise. As noted by Fourie: 'Ideology has a close connection to language and to the mass media that... are the main means for the communication of ideology in society and manipulating people’ (2005:311).

Ideologies are generally perceived as negative forces in society- as a 'system of false beliefs' or 'a process for the production of meanings to support social domination of one group over another' (Fourie, 2005:312). In this sense one can see that 'for those engaged in the promotion of particular ideas the media are among the primary contemporary battlegrounds' (Croteau \& Hoynes, 2003:161).

The negative view of ideology inspires most of the critical theories of the media's role in society. The role of ideology as "social cement", bringing together various social classes, also forms the basis of the Marxist theories. According to these theories, ideology is "false consciousness" in the sense that it only serves the interest of the elite or dominant ideology, thereby persuading other classes that their state of subordination is the natural order of society (Fourie, 2005:315).

Marxist scholars believe that the media play an important and active role in this process, acting as 'agencies of social control' that 'reinforce domination by communicating the ideology of the dominant class, provide legitimacy to the existing social status quo, manipulate and control the ways of thinking of the dominant groups and are responsible for creating false consciousness' (Fourie, 2005:315).

\section{Relaxing Marxism}

Whereas Marxist theories tend to neglect (among other things) personal autonomy and the audience's power to challenge dominant ideologies as portrayed in the media, whilst attaching a lot of meaning to the influence of material and economic interests on ideology, neo-Marxist and cultural studies theories pay more attention to how audiences respond to ideologies (McQuail, 2005:96).

\section{Althusser's symbolic universe}

Louis Althusser argued that ideology is produced by Ideological State Apparatuses (ISA's), including institutions like family, school, language and mass media, for example. ISA's, Repressive State Apparatuses (such as the military and police) and economic conditions 'socialise and prepare people to accept their society as it is' (Fourie, 2005:316).

According to Althusser's approach, 'people cannot have a direct and an objective view of a reality as there is no way that one could step out of ideology to some non-ideological position and measure how ideology distorts and misrepresents true reality. People live, experience and give meaning to their world and society by 
using a system of representations such as language, pictures and the mass media... It is as if people live in a symbolic universe' (Fourie, 2005:317).

The media's role in a society, according to Althusser's view, is therefore to represent certain aspects of the universe to society. Such representation will always be filled with ideologies and will never be a mirror-image of reality, but it still enables people to position and identify themselves within representations - something Althusser referred to as ‘interpellation' (Fourie, 2005:318).

\section{Hegemony and the media's support of ideologies}

Antonio Gramsci's notion of hegemony assumes that ruling groups lose the need for force in asserting their power by making use of culture and ideology - essentially by gaining consent. 'Consent is something that is won; ruling groups in a society actively seek to have their worldview accepted by all members of society as the universal way of thinking' (Croteau et al., 2003:166).

The media's role in society, according to hegemony, is to help ruling parties in manufacturing consent - in making certain social structures and relationships seem normal and natural; in lending them 'a kind of permanency and legitimacy that elevates them to the realm of the uncontested' (Croteau et al., 2003:167). Most of the media are therefore servants of the dominant, merely reflecting that which is beneficial to the parties in power.

In South Africa the prime example of a dominant group's values becoming normalised is that of apartheid, which was based on the assumption and ideology that one race is 'naturally superior to others' (Croteau et al., 2007:167).

Of course, as noted by Gramsci, there will always exist examples of counterhegemonic forces - 'oppositional, psychocultural force[s], through which revolutionaries subvert the ruling-class ideology and substitute democratic socialism for capitalism' (Simms, 2000). These are produced by intellectuals that 'establish anti-ruling class institutions and platforms of expression that challenge the right-torule of the dominant group' (Simms, 2000). The question in a South African context, however, is whether the media reinforced hegemony or counter-hegemony.

After 1994, the Truth and Reconciliation Committee (TRC) held special hearings for the media in order to determine two fundamental questions: "Could the media under apartheid be held responsible for the perpetration of gross human rights violations? Moreover, to what extent could they be held responsible for creating a climate in which violations occurred unhindered?' (TRC Final Report, 1998).

It was found that the racist ideologies of the apartheid government also permeated the media - that the media (especially the mainstream newspapers and the SABC) 'helped sustain and prolong the existence of apartheid' (TRC Final Report, 1998).

Only by exception did the South African media attempt to carry a message different to that of the dominant ideology. The Vrye Weekblad was an Afrikaans newspaper, one of few, that was adamant to challenge the dominant apartheidideology.

The former editor of this newspaper, Max du Preez, testified at the TRC media hearings that 'If the mainstream newspapers and the SABC had reflected and followed up on all these confessions and revelations [as revealed by the newspaper], every single one subsequently proved to have been true, the government would have been forced then to stop, to put a stop to the torture, the assassinations and the dirty tricks. It would have saved many, many lives’ (TRC Final Report, 1998). 
It is however important to qualify Du Preez's statement by adding that the media's inaction could also be blamed on the National Party government's use of various laws to restrict the operation of the media, as well as the influence of advertisers (needing the support of politicians and, as such, not ascribing to possibly damaging reports) - among various other factors.

\section{Critical cultural studies}

The manner in which the media produces certain images of the world in order to give meaning to the world (including hegemony) was emphasised in Stuart Hall's studies. His approach, which forms part of the cultural studies discipline, furthermore allowed the expansion of the critical studies approaches beyond its original occupation with ideological domination (McQuail, 2005:116).

According to the critical studies approach, the media have the power to give meaning to certain events in particular ways (whilst marginalizing other 'truths') thereby carrying dominant ideologies and assumptions. It is thus clear that the media does not just act as a mirror reflecting the world and reality. As Hall writes, 'representation is a very different notion from that of reflection. It implies the active work of selecting and presenting, of structuring and shaping; not merely the transmitting of an already-existing meaning, but the more active labour of making things mean' (cited in Croteau et al, 2003:168).

\section{POWER TO THE AUDIENCE?}

Besides rejecting the notion that the media merely holds up a mirror to society, the cultural studies' scholars also focused on the way in which texts are interpreted by audiences. Whereas mass audiences were originally described as something that was an object of manipulation - It did not act for itself but was, rather, 'acted upon' (McQuail, 2005:56) - Stuart Hall emphasised the power audiences possess.

Audiences' power mostly lies in the way in which they can interpret media texts, which are polysemic in the sense that they have various possible outcomes (Wasserman, 2007:3). According to Hall, texts may be read in one of three manners. With the dominant or preferred way, the text is accepted as it is encoded; whereas the negotiated way of reading only accepts some of what is presented, and the alternative or oppositional way of reading opposes the preferred meaning (Wasserman, 2007:3).

As such, as McQuail writes, 'Even if most people in a class society are subordinated, they have a degree of semiotic power... that is, the power to shape meanings to their own desires' (2005:118). Whether or not this power is actually exercised is another issue - according to McQuail (2005:119) 'there is not much empirical support for the theory that media texts are decoded in oppositional ways'.

It may be concluded that the possibility exists that that which is reflected by the media will be qualified by the importance attached to it by audiences - and in an age where mass media permeates everyday life to an enormous extent, it is submitted that audiences will become ever more critical of the reality reflected by the media.

\section{OTHER THEORIES}

Certain other theories also prescribe possible roles for the media in a society, but although concerned with different influences on the media, these (except the critical political economy theory) do not have such a strong emphasis on ideology. 


\section{Mass society theory}

The mass society theorists are generally concerned with the amount of power that the mass media can have in a society. They also believe that institutions that wield power are dependent on another and, as such, the media become integrated with sources of social power and authority. In this sense, they warn, 'content is likely to serve the interests of political and economic power holders’ (McQuail, 2005:94).

Although it may be noted that this theory has changed to allow for the fact that the media is today "probably less "massive", one-directional and distant, and more responsive and participant' (McQuail, 2005:61), the media is still more than just an innocent bystander holding up a mirror to society. The media is a 'causal factor' in society (McQuail, 2005:94), possessing power that is often abused. 'They are not always benign in their working. They can exert power without accountability and destroy individual lives,' warns McQuail (2005:94). “They can undermine as well as support the democratic political process".

\section{Critical political economy}

The critical political economy theory, which also gained more prominence after the stricter Marxist-theories were somewhat relaxed, focuses on the relationship between a society's economic structure and media industries and the effect that this relationship has on the ideologies to be found within media content (McQuail, 2005: 100).

The consequences of these economic influences can be found in various occurrences today, including the concentration of media ownership (Media24 in South Africa, for example), the avoidance of risks, the reduction of independent media and neglect of poorer audiences (McQuail, 2005:100).

Following this approach, it is clear that media content does not merely reflect reality - reality is coloured, albeit in an indirect rather than direct manner, by the economic interests of media industries.

\section{Social Constructionism}

The social constructionism theory is an open-ended approach supporting the idea that reality is created by humans and that the media plays an important role in influencing 'what people believe to be reality' (McQuail, 2005:101). Examples of social constructionism at work can be found in the 'unthinking, but unceasing, promotion by media of nationalism, patriotism, social conformity and religion' (McQuail, 2005:101).

The construction of news is one of the focus points of the social constructionist theorists (see p.6). In essence one can summarise this theory as the 'processes by which events, persons, values and ideas are first defined or interpreted in a certain way and given value and priority, largely by mass media, leading to the (personal) construction of larger pictures of reality' (McQuail, 2005:101).

The media's role in society is thus, in accordance with this approach, not merely to act as a mirror reflecting reality, but also to reproduce a selective view of reality - one that is of course burdened by the weight of hidden ideologies.

\section{Communication technology determinism and the information society theories}


Both the communication technology determinism and the information society theories are more media-centric in the sense that they, unlike the other theories, operate from the assumption that the media acts as 'primary moulders and movers within a society' (McQuail, 2005:108). It can perhaps be argued that this view corresponds to the idealistic view of the media's role in society.

Scholars within the communication technology tradition tend to believe that changes in communication technologies over the ages also lead to changes in society, or social revolutions. The approach has been softened over the years in the sense that observers now realise that innovation in communication will not easily be the only reason for societal change (McQuail, 2005:104).

The information society theorists place less emphasis on the content produced by the media, rather focusing on the way in which people become dependent on information - especially electronic information. Van Dijk, as cited in McQuail, defines this society as one that is increasingly organising its relationships in media networks which are gradually replacing or complementing the social networks of face to face communication' (2005:106).

Clearly both these theories do not support the approach that the media's role in society is to merely 'hold up a mirror to society'. The theorists in these disciplines attach much greater importance to the role that the media plays in society as a primary factor in the process of change.

\section{THE FUNCTIONALIST APPROACH: A NORMATIVE VIEW OF MEDIA AND SOCIETY}

The functionalist approach to the media's role in society operates from the basis that the media maintains the basic needs of society by fulfilling various functions. 'As powerful socialisation instruments they should function towards integration, harmony and cohesion, whether it is through the information, entertainment and/or education they provide' (Fourie, 2005:265).

The normative view is also concerned with the hurdles the media can face in attempting to exercise their supposed functions. Siebert, Peterson and Schramm suggest in their book, Four theories of the press (1963), that the media generally "takes on the form and colouration of the social and political structures within which it operates. Especially it reflects the system of social control” (McQuail, 2005:176).

The authors define four different press systems in the world - something which was later expanded on by two newer theories that suit modern developments (Fourie, 2005:269).

\section{Normative theories of the press}

The authoritarian theory prevails in dictatorial societies or in societies where freedom of the press does not enjoy much protection. According to the theory, 'the only function of the press is to publicise and to propagandise the government's ideology and actions' (Fourie, 2005:270). An example of a modern-day authoritarian press would be that of Zimbabwe, and South Africa was itself an example until a few years ago.

The libertarian theory operates from the standpoint that the press should be free from any influence or control, especially from that of the government. This approach cannot always be interpreted literally, especially in a South African context 
where conflicting rights and interests have to be weighed against each other and others might at times take preference over the liberty of the press, according to the 1996 Constitution.

The social responsibility theory entails, among other things, that the media accepts certain responsibilities towards society, fulfils responsibilities (meeting professional standards), is responsible and able to be representative of society (Fourie, 2005:272).

The Soviet communist press theory reflects a very strict view of the role of the press, where the press reflects the interests of the working class and, among other things, a 'complete and objective view of the world and of society in terms of Marxist-Leninist principles’ (Fourie, 2005:273).

The development theory is a new theory that applies to developing countries where the media can be used to 'promote national development, autonomy and cultural identity' (Fourie, 2005:273). As with the libertarian approach certain liberties sometimes take preference over others.

In South Africa, for example, our constitution foresees the possibility that certain fundamental human rights may clash with another. When this happens, a balancing exercise is required where the two rights are weighed up against another.

The right to privacy (section 14 of the constitution) is one right that frequently clashes with the right to freedom of expression (including press freedom). Earlier this year, for example, an interdict was granted against the magazine Huisgenoot/You from publishing the name of the 'uncle' who had allegedly molested singer Robbie Klay on the basis of the right to privacy (Brand, 2008).

The democratic-participant theory is explained by Fourie (2005:274) as 'a reaction to the trends towards commercialisation and monopoly-formation in privately-controlled mass media', especially in developed countries. This theory advocates more interaction and development between society and the media, or horizontal instead of vertical communication, so that the communicator and recipient are on equal footing.

The normative view of the media's role in society therefore prescribes different roles for the media in a society, depending on the specific social and political circumstances of a country. The fact that social and political circumstances have an effect on the different roles that the media should play in a particular society in itself indicates that the media will never be able to simply fulfil the role of 'holding up a mirror to society'. Following the normative view, the media does not just translate reality, but translates reality relative to political or social circumstances.

\section{CONCLUSION}

Although journalists may often argue that they simply hold up a mirror to society, various theories as to the media's role in a society suggest that that which the media presents to society much more, or should one say less, of reality.

The various media roles that these theories describe, as well as the effect that factors named in these theories can have on media content, seem to prove that the media's role is not just to provide society with mirror-images of reality. In any case, that which is represented by the media as 'reality' is far from it. As such one may argue that the various theories that describe and prescribe the media's role in society have shattered the media's mirror on reality. 


\section{REFERENCES}

Brand, R. 2008. A tale of two singers, a child molester, the media and the law. http://www.thoughtleader.co.za/robertbrand/2008/02/15/a-tale-of- twosingers-a-child-molester-the-media-and-the-law/. Accessed: 2008-05-12.

Campbell, R., Martin, C. \& Fabos, B. 2002. Media \& Culture. Boston: Bedford/ St Martin's.

Croteau, D. \& Hoynes, W. 2003. Media/Society. Thousand Oaks: Pine Forge Press.

Du Preez, M. 2005. Oranje, blanje blues: 'n Nostalgiese trip. Cape Town: Zebra Press.Fourie, P.J. (Ed.). 2005. Media Studies. Lansdowne: Juta.

Maggo, Eduan. 2006. Crazy-foto’s ‘was nie verkeerd'. Die Burger: 2006-05-18:2.

McQuail, D. 2005. McQuail's Mass Communication Theory. (Fifth edition). London: Sage.

Simms, R. 2000. Black theology, a weapon in the struggle for freedom: a Gramscian analysis. Race and Society 2(2):165-193.

Taljaard, Jan. 2006. Burger-redakteur, lesers in skerp debat oor moordfoto’s. Die Burger, 2006-04-29.

Truth and Reconciliation Commission Final Report. 1998. TRC Final Report. Institutional Hearing: The media.

http://www.polity.org.za/polity/govdocs/commissions/1998/trc/volume4.htm. Accessed: 2008-03-02.

Wasserman, H. 2007. Media \& Society: news media, representation and power. [Course notes]. Stellenbosch: University of Stellenbosch. 